\title{
TUBERCULOSIS ARTHRITIS MIMICKING THE JOINT DISEASE ACTIVITY OF ANTI-SYNTHETASE SYNDROME
}

\author{
Janaína Baggio ${ }^{1, \star}$, Carla Baleeiro Rodrigues Silva ${ }^{1}$, Andre Silva Franco ${ }^{1}$, Guilherme Guimarães Moreira Balbi ${ }^{1}$, Heitor Furlan \\ Giordano ${ }^{1}$, Henrique Helson Heter Dalmolin ${ }^{1}$, Henrique Ayres Mayrink Giardini ${ }^{1}$, Lissiane Karine Noronha Guedes ${ }^{1}$, Rosa Maria \\ Rodrigues Pereira ${ }^{1}$
}

1.Universidade de São Paulo, São Paulo (SP), Brazil.

*Corresponding author: jana9baggio@gmail.com

\section{BACKGROUND}

Antisynthetase syndrome (ASS) is an idiopathic inflammatory myopathy. The association of extrapulmonary tuberculosis (TB) and rheumatologic diseases is widely recognized, as these patients had an immunosuppressive state due to disease activity or drug induced immunosuppression. We described the case of a patient with a recent diagnosis of ASS who evolved with refractory joint manifestation during the use of immunosuppressants, being later diagnosed with septic arthritis due to tuberculosis.

\section{CASE REPORT}

Female, 58 years old, diagnosed with ASS 3 years ago, with proximal muscle weakness, fever, Raynaud's phenomenon. She had anti-Jo-1 negative, ANA 1/160 fine speckled cytoplasmic and anti-Ro and anti-La positive ( $>200 \mathrm{U} / \mathrm{mL}$ ). Muscle biopsy with rare necrosis, presence of mild endomysial inflammatory reaction. Initial treatment with methylprednisolone pulse and association of methotrexate and mycophenolate mofetil. During follow-up, the patient presented recurrent soft tissue infections, in addition to polyarthritis refractory to the combination of several immunosuppressive drugs. In November 2020, the patient began to present arthritis of large joints, especially in the knees and shoulders, in addition to fever and adynamia. She denied respiratory complaints and muscle weakness. On physical examination, she presented arthritis in the right knee, with no changes in other systems. On $\mathrm{MRI}$, the right knee presented with joint effusion, synovitis and pericapsular soft tissue edema, in addition to elevated inflammatory tests (CRP $120 \mathrm{mg} / \mathrm{L}$; ESR $122 \mathrm{~mm} / \mathrm{h}$ ), high serum ionic calcium (5.9 mg/dL), PTH low ( $<6 \mathrm{pg} / \mathrm{mL}$ ), raising the hypothesis of granulomatous disease. Due to the suspicion of septic arthritis secondary to Mycobacterium tuberculosis, a chest CT was performed which showed a budding tree in the apex of the right lung. The investigation was continued with bronchoalveolar lavage showing a positive search for acid alcohol resistant bacillus and the synovial biopsy of the right knee showed the presence of caseous granuloma and a positive synovial culture for Mycobacterium tuberculosis. The patient started treatment with tuberculostatic drugs, opting to maintain low doses of methotrexate $10 \mathrm{mg} /$ week and prednisone $10 \mathrm{mg} /$ day. The patient presented partial improvement of the joint condition; however, two months after hospital discharge, she was admitted to another service with a diagnosis of respiratory infection, progressing to septic shock and death.

\section{CONCLUSION}

Although arthritis is one of the typical and frequent manifestations of ASS that can manifest itself, in the face of a refractory joint condition, it is imperative to actively seek an associated infectious condition, mainly M. tuberculosis.

\section{KEYWORDS}

Antisynthetase syndrome, Tuberculosis, Arthritis. 